\title{
The Effect of Teaching Strategic Competence on Speaking Performance of EFL Learners
}

\author{
Goudarz Alibakhshi \\ Yasouj University, Iran \\ Email: alibakhshi_goodarz2000@yahoo.com \\ Davood Padiz \\ Yazd University, Iran \\ Email: davoud.padiz@gmail.com
}

\begin{abstract}
Communicative strategies have always been of much concern to applied linguists. Whether teaching communicative strategies has any significant impact on second language learners' speaking or not has also controversial among language teachers. This study aimed at investigating the effect of explicit teaching of some of the communicative strategies (CSs) on language performance of Iranian language learners of English. It was also an attempt to study the stability of teaching CSs. The participants of the study were 60 male and female language learners. The experimental group received a $\mathbf{1 0}$-week-treatment on CSs. The data were gathered through three oral production tests consisting of the same tasks including group discussion, story retelling, and picture description. The data were analyzed through descriptive and inferential statistics (Chi-square test). The results of the study indicated that there was significant difference between control and experimental groups in the use of CSs; whereas, the results of the first posttest showed that there was a significant difference between the groups in the use of seven out of the nine strategies. Moreover, the results indicated that the effect of teaching CSs was stable even after a long interval.
\end{abstract}

Index Terms - teaching communication strategies, teaching stability, Iranian language learners, speaking proficiency

One of the most important and at the same time controversial issues over the past few decades has been teachability of communication strategies (CSs). Most experienced teachers believe that a prevalent problem that a lot of language teachers and learners face is learners' reluctance to participate in conversations and other speech events. Hence, they would rather shift to their native language to get their messages across or try to be silent which leads to a communication break. Although this disinclination can be attributed to such affective factors as lack of motivation or self-confidence and embarrassment or to such external factors like impractical language teaching methods and materials, it can mostly be the result of lack of communicative strategies necessary for L2 speakers when faced with communication problems. Therefore, this study is an attempt to find out whether CSs can be taught or not. Moreover, it aims at specifying the durability and stability of CSs after the treatment. In doing so the following research questions were raised.

1. What is the effect of teaching strategic competence on speaking performance of Iranian English language learners?

2. Is the effect of teaching communicative competence stable after a long time?

\section{LITERATURE REVIEW}

Communication strategies are defined as the techniques used by the learners when there is a gap between their knowledge of the language and their communicative intent (Wenden, 1986). What kind of problems can a speaker encounter? The following figure shows a diagram which is adopted from a well-known study by Farch \& Kasper (1983).

Quite a few empirical investigations (to name just a few, Selinker, 1972; Varadi, 1973; Tarone, 1977) have been carried out to study the effectiveness of teaching CSs. Although these studies have been done in various languages by different people, they were aimed at the verification of successfulness or unsuccessfulness of teachability of CSs (Dornyei, 1995). Also, Savignon (1972) reported on a pioneering language teaching experiment involving a communicative approach, which, for the first time, included student training in CSs ( or, as she termed them coping strategies) . Palmer (1981) noticed that some subjects with obviously limited grammatical structures and vocabularies described the pictures in terms of their placement on the page, in terms of how dark or light they are, or how big or small. These subjects appear to have adopted the strategy of ignoring the propositional content of the pictures and communicating instead about the nonverbal visual (the lines and shapes) used to represent them. Since these early studies, much research has been done to identify and classify CSs; however, far less attention has been paid to the question of whether these strategies could be integrated into second or foreign language teaching programs. In other words, to date, not many have investigated explicit teachability of communication strategies. 
The review of literature indicates that there is no general consensus on teaching oral communication strategies and the results reported have been rather mixed (Mc Donough, 2006). Generally speaking, there are two broadly diverging schools of thoughts on CSs (McDonough, 2006). One approach lays more emphasis on the cognitive processes involved in selecting one or another strategy, and proponents of this approach ( to name just a few, Bialystok, 1990; Konishi \& Tarone, 2004) argue that cognitive processes are not influenced by instruction and because CSs are part of cognitive processes, they are not teachable. The proponents of the other approach (e.g. Dörnyei, 1995; Konishi \& Tarone, 2004; Lam, 2005), however, put emphasis on the linguistic expressions used in identifying types of CSs, and believe in the necessity of teaching these linguistic expressions or communicative strategies needed for effective L2 communication language use. The review of literature indicated that several interventionist studies, although insufficient and small, have been carried out to delve into the nature of teaching communication strategies. The recent ones are reviewed in the following parts.

Dornyei (1995) relates a pilot 6-week training experiment with 109 students in Hungary in the use of three CSs namely topic avoidance and replacement, circumlocution, using fillers and hesitation devices. The findings indicated that there was improvement in the use of CSs related to both the quality of circumlocutions and the frequency of the fillers and circumlocutions in the oral post-test consisting of topic description, cartoon description, and definition formulation. Dörnyei's (1995) study illuminates the views that CSs may be teachable and that patterns of students' strategy use may be significantly changed by instruction.

Salamone and Marsal (1997) report an experiment which aimed to investigate the impact of communication strategy instruction on two intact French classes of 12 undergraduates each. The treatment class received instruction in the use of circumlocution as well as strategies to cope with lexical difficulties, and the comparison class served as a control class. All participants completed pre- and posttest that elicited explanations of concrete nouns, abstract nouns, and shapes. The findings showed that both groups showed significant improvements over time, but there were no significant statistical differences between the two classes in the post-test. The tests administered in this study were, however, written rather than oral. This puts the validity of employing a written test to assess the impact of CSs for oral communication into question.

Scullen and Jourdain (2000) examined the effect of the explicit teaching of oral circumlocution on undergraduate learners studying French as a foreign language in an American university. The treatment group was explicitly taught to use super-ordination, analogy, function, and description strategies immediately prior to the first, the second and the third practice sessions, respectively. The Participants in both control and experimental groups completed a pre-test, three practice sessions, and a post-test. The results indicated that both the treatment and control classes made significant gains in successful identification over time, but the between-group difference on the post-test was not significant. Given the short period of training and the small group sizes, further investigation is no doubt desirable.

Rossiter (2003) reports the effects of communication strategy instruction on strategy use and on second language performance. Two classes of adult immigrants in Canada participated in this study. One class received 12 hours of direct communication strategy training, and the second served as a comparison group. Two oral tasks (picture story narratives, object descriptions) were administered in Week 1, Week 5, and Week 10. The post-test results showed a direct effect in favor of the communication strategy condition on a range of strategies used in the object description task, which was more effective than the narrative in eliciting communication strategies. Nonetheless, the author concludes that strategy training appeared to have little impact on learners in terms of task performance.

Regarding the effects of communicative strategy training on language performance, Nakatani's (2005) study produced rather different findings from Rossiter's (2003). Nakatani (2005) focuses on awareness-raising training in oral communication strategy use. In this experiment, the subjects, being 62 Japanese female learners of English were involved and divided into the strategy training group and the control group. Over 12 weeks, the former received metacognitive strategy training whereas the latter received only the normal communication course. The strategy group was also taught CSs that could help students learn more of the language such as asking for clarification, checking for comprehension, and paraphrasing. The effects of training were assessed by speaking test scores, transcription the data from the tests, and retrospective protocol data for their task performance. The findings revealed that participants in the treatment group improved their oral proficiency test scores, but those in the control group did not.

\section{METHODOLOGY}

\section{A. Participants}

The participants of the study were 6o male and female Iranian learners of English with the age range of 18-20. They were all studying English in language institutes located in Yasuj city, the center of Kohgiluyeh \& Buyerahmad Province in Iran. All participants were born in Iran, spoke Persian as their first language, didn't speak English out of classroom situation, and they had at least four semesters of formal language instruction. The subjects participated in English classes to enhance their conversational skills; however, they didn't take part in any other English classes. Most importantly, the subjects neither took any course of CS training nor encountered any teacher teaching CSs, and any materials involving CSs; although, perhaps indirectly, unintentionally, and unconsciously, they in their language and interlanguage experience gained some CSs of which they were not informed in a specialized and conscious manner. The 
participants were randomly divided in two groups. They were then randomly assigned into experimental and control groups.

\section{B. Instruments}

Undoubtedly one of the most important steps in this study was data collection. To do this, in this study some instruments including a pretest and posttest each consisting of the same number of tasks were used. The two tests were oral and measured speaking performance of the language learners. The reliability of the two tests was estimated through inter-rater reliability approach. That is, the speaking performance of the participants and the CSs used in their speaking was evaluated by two different raters. The coefficient correlation between the ratings of the two raters in both tests exceeded .8 which is an acceptable index for reliability. Each test consisted of the same types of tasks which will be explained separately in the following sections.

\section{Tasks}

One of the most significant steps taken in this study was specifying some tasks which were done by the participants in order to make them produce themselves orally. Not any task was appropriate for our project because we needed those tasks which could pave the way for elicitation of CSs to a large extent. Although there have been a lot of tasks produced by various researchers in this realm, and although most of them were found working, we tried to select those whose degree of comprehensiveness seemed a bit more than the rest. Moreover, to avoid complexities of the study, we decided to choose just three of these tasks known as: (a) group discussion (b) retelling Persian short stories in English, and (c) picture description.

\section{Data Analysis}

The data of the study were analyzed through different statistical procedures including descriptive and inferential statistics. As we were concerned with frequency of communicative strategies in the participants' oral production, the best statistical test is a nonparametric Chi-square test. In this study, we had three tests pretest, posttest 1 and posttest2. The results for each test are presented in the following sections.

\section{RESULTS}

\section{A. Results and Discussion of the Pretest}

The purpose of the pretest was to confirm that there was no initial difference in the use of each communicative strategy by the participants of the study. The results are presented in table $1 \& 2$.

TABLE 1:

DESCRIPTIVE STATISTICS FOR THE PRETEST

\begin{tabular}{rrrrrrrrrr} 
Groups & \multicolumn{10}{c}{ Fescrequency of Communicative Strategies } \\
\hline & A & AP & R & LS & WC & AS & C & S.repe. & S.repa. \\
\hline Experimental & 230 & 280 & 156 & 466 & 124 & 262 & 178 & 198 & 112 \\
\hline Control & 230 & 280 & 130 & 452 & 128 & 250 & 160 & 188 & 100 \\
\hline
\end{tabular}

( $\mathrm{A}=$ avoidance, $\mathrm{AP}=$ approximation, $\mathrm{R}=$ restructuring, $\mathrm{LS}=$ language switch, $\mathrm{WC}=$ word coinage, $\mathrm{AS}=$ appeal for assistance, $\mathrm{C}=$ circumlocution, S.repe $=$ self-repetition, and $\mathrm{S}$. repa $=$ self-repair)

TABLE 2:

CHI-SQUARE TESTS FOR EACH COMMUNICATIVE STRATEGY BY BOTH GROUPS

\begin{tabular}{rrrr}
\multicolumn{2}{c}{ CHI-SQUARE TESTS FOR EACH COMMUNICATIVE STRATEGY BY BOTH GROUPS } \\
& Chi-s quare & Degree of freedom & Significance \\
\hline Avoidance & .22 & 1 & .63 \\
\hline Approximation & 1.2 & 1 & .5 \\
\hline Restructuring & .33 & 1 & .45 \\
\hline Language switch & .78 & 1 & .7 \\
\hline Word coinage & .36 & 1 & .6 \\
\hline Appeal for assistance & .32 & 1 & .66 \\
\hline Circumlocution & .49 & 1 & .23 \\
\hline Self-repetition & .38 & 1 & .40 \\
\hline Self-repair & .62 & 1 & .48 \\
\hline
\end{tabular}

As the results in table 2 indicate, there is no significant difference between frequencies of communicative strategies used in oral production by the participants of both groups. That is, they used the same number of communicative strategies.

\section{B. Results of the First Posttest}

The posttest was administered to measure the frequency of each communicative strategy in the oral production of the participants. The frequency of each CS and the inferential statistics (Chi-square) are presented in tables $3 \& 4$, respectively. 
TABLE 3:

DESCRIPTIVE STATISTICS FOR THE POST-TEST

\begin{tabular}{rrrrrrrrrrr} 
Groups & \multicolumn{1}{c}{ Frequency Communicative strategies } \\
\hline & A & AP & R & LS & WC & AS & C & S.repe. & S.repa. \\
\hline Experimental & 74 & 298 & 114 & 112 & 100 & 470 & 284 & 478 & 160 \\
\hline Control & 206 & 238 & 100 & 320 & 80 & 232 & 164 & 166 & 104 \\
\hline
\end{tabular}

TABLE 4:

CHI-SQUARE FOR EACH COMMUNICATIVE STRATEGY BY BOTH GROUPS IN POSTTEST

\begin{tabular}{rrrr} 
& Chi-square & Degree of freedom & Significance \\
\hline Avoidance & 92 & 1 & .000 \\
\hline Approximation & 6.7 & 1 & .000 \\
\hline Restructuring & .9 & 1 & .33 \\
\hline Language switch & 100 & 1 & .000 \\
\hline Word coinage & 2.2 & 1 & .13 \\
\hline Appeal for assistance & 80 & 1 & .000 \\
\hline Circumlocution & 90 & 1 & .000 \\
\hline Self-repetition & 101 & 1 & .000 \\
\hline Self-repair & 11 & 1 & .001 \\
\hline
\end{tabular}

The main purpose of teaching was to help the participants of the study to decrease two of the communicative strategies: avoidance and language switch but to increase the use of the other seven strategies. More specifically, the participants were trained to replace avoidance with appeal for assistance either directly or indirectly. As Table 3 shows, the participants in the experimental group used avoidance strategy 73 times but the control group members used this strategy 206 times. The results of Chi-square test $(\mathrm{X} 2=, \mathrm{d}, \mathrm{f}=1$, sig. $=.000)$ also confirmed that there was a significant difference between the use of this strategy by the two groups. Due to the significant difference between the use of this strategy in the pretest and the posttest, it could be strongly discussed that teaching could significantly influence the use of this strategy by Iranian EFL learners.

Language switch like avoidance strategy and unlike the other strategies was taught and the learners were expected to avoid this strategy in their oral productions. As expected, the results showed that there was a significant difference between the frequency of language switch use by experimental and control groups $\left(X^{2}=100, d, f=1\right.$, sig. $=.000$. The descriptive statistics in table 1 also indicates that, prior to the instruction, the participants in experimental group used language switch strategy 466 times; whereas, after the instruction the participants used this strategy 112 times.

Unlike the above mentioned strategies, we expected the learners to use the other communicative strategies in their oral productions as many times as they can. The results in table 4 indicates that the difference between the use of restructuring $\left(\mathrm{X}^{2}=.9, \mathrm{~d}, \mathrm{f}=1\right.$, sig. $\left.=.33\right)$ and word coinage $\left(\mathrm{X}^{2}=2.2, \mathrm{~d}, \mathrm{f}=1\right.$, sig.= .12$)$ by the participants of the study was not significant. Therefore, it could be strongly argued that these strategies are not teachable. Difficulty of the strategy, lack of enough practice, and teaching and learning related issues which are beyond the scope of this study may be the reasons for teaching inefficiency.

In terms of the use of approximation strategy, as expected, the results in table 4 indicate that there is a significant difference between the two groups $\left(\mathrm{X}^{2}=6.7, \mathrm{~d}, \mathrm{f}=1\right.$, sig. $\left.=.01\right)$. That is, the experimental group outperformed the control group and in comparison with the pretest, they used this strategy in their oral production many times.

Furthermore, it could be said that_appeal for assistance can be used directly or indirectly. As Tables $2 \& 3$ illustrate, both groups frequently used this strategy in their productions. Undoubtedly, the use of this strategy is resulted from the curious nature of human beings. However, we attempted to make the participants aware of the significance of this strategy through treatment. Even though both groups used this strategy many times, the results of inferential statistics in table 3 shows a significant difference between the use of this strategy by the two groups $\left(X^{2}=100, \mathrm{df}=1\right.$, sig.=.000). That is, the experiment group outperformed the control group and it could be discussed that teaching can influence the use of this strategy by language learners to a great extent.

Finally, the significant difference between the use of circumlocution $\left(X^{2}=100, \mathrm{df}=1\right.$, sig.=.000) confirms that the participants were able to describe the target word in English though they could not express the object itself. Also, the difference between the uses of self-repetition by the two groups verifies that after the treatment the participants in the experimental group did their best to use this strategy whenever they could not remember the intended words. It could also be discussed that language themselves whenever they made mistakes in their production. Therefore, in line with Palmer (1990) it could be discussed that CSs should be taught to language learners so that they can have a better effective communication.

\section{Results of the Second Posttest}

The second posttest consisting was administered to only experimental group to investigate whether teaching CSs has a long lasting effect or not. The frequency of each communicative strategy used by the participants was counted and compared with the frequencies of CSs in the first posttest. The results are shown in tables $5 \& 6$, respectively. 
TABLE 5:

DESCRIPTIVE STATISTICS FOR THE EXPERIMENTAL GROUP POSTTESTS $1 \& 2$

\begin{tabular}{llllllllll} 
Tests & \multicolumn{1}{c}{ Frequency Communicative strategies } \\
\hline & A & AP & R & LS & WC & AS & C & S.repe. & S.repa. \\
\hline Posttest 1 & 74 & 298 & 114 & 112 & 100 & 470 & 284 & 478 & 160 \\
& & & & & & & & & \\
\hline Posttest 2 & 70 & 160 & 120 & 160 & 97 & 380 & 270 & 460 & 153 \\
\hline
\end{tabular}

TABLE 6:

CHI-SQUARE FOR COMPARING THE CONTROL GROUP'S USE OF CSS IN POSTTES1 \& 2

\begin{tabular}{llll}
\hline & Chi-square & Degree of freedom & Significance \\
\hline Avoidance & .92 & 1 & .31 \\
\hline Approximation & 60 & 1 & .000 \\
\hline Restructuring & .9 & 1 & .33 \\
\hline Language switch & 66 & 1 & .000 \\
\hline Word coinage & 2.2 & 1 & .13 \\
\hline Appeal for assistance & 80 & 1 & .000 \\
\hline Circumlocution & 6 & 1 & .32 \\
\hline Self-repetition & 76 & 1 & .000 \\
\hline Self-repair & 4 & 1 & .13 \\
\hline
\end{tabular}

The results of the study in table 6 indicate that there was a significant difference between the use of approximation $\left(\mathrm{X}^{2}=60\right.$, sig.=.000), appeal for assistance $\left(\mathrm{X}^{2}=80\right.$, sig.=.000) and self-repetition $\left(\mathrm{X}_{=}^{2}=70\right.$, sig.=.000 $)$. Moreover, the results indicate that there is a significant difference in the use of language switch strategy in the first and the second posttests $\left(\mathrm{X}^{2}=66 \mathrm{sig} .=.000\right)$. However, as it can be seen from table 6 , there is no difference between the frequencies of the other strategies in both posttests.

\section{DISCUSSION}

In order to obtain empirical data regarding the potential usefulness of CS instruction, an experiment was carried out, focusing on nine different types of strategies. The results of the first post tests showed improvement in quantity of CS use by the participants of the experimental groups. In other words, in seven out of nine CSs the treatment group outperformed the non-treatment group. The significance difference between both groups provided evidence that the increase in the frequency of almost all CSs - avoidance, approximation, language switch, appeal for assistance, circumlocution, self-repair, self-repetition- could indeed be attributed to the treatment. This finding is in line with the findings of Palmer (1990); however, the same thing cannot be generalized to restructuring and word coinage which seem to have resulted from the natural difficulty hidden in these two strategies. Consequently, regarding question 1 , the study has provided evidence to support the value of CS instruction and the experimental group did better than the comparison group on the strategies elicited from the participants' oral production in the expected tasks namely: group discussion, story-retelling, and picture description. The results of the first pos-test; therefore, suggest that CS instruction might have a positive effect on enhancing learners' performance. And finally in reply to research question 1 , as mentioned above, it could be firmly argued that teaching CSs has a positive effect on language performance of Iranian learners' of English.

Regarding research question 2, which aimed at evaluating the stability of the CSs, findings from the second posttest indicate that a three-month interval had different impacts on the frequency of strategy use by the participants of the treatment group. In other words, the second post-test was administered to test the extent to which the target CSs remain stable after the expected duration. The results show that the nine communicative strategies, on the basis of their stability after the treatment, could be divided into three categories.

a) Three of the communicative strategies namely approximation, appeal for assistance, and self-repetition had turned out to be significantly different from their corresponding items in the post-test taken by the control group; whereas, in the second post-test and after the interval they lost their effect and frequency of their use seemed to decrease rapidly. It could be argued that language learners need repeated training and awareness about these three strategies. There may be some other influential factors which need further exploration.

b) Language switch with a high frequency of use in the participants' production and also with a significant difference from the control group in the first post-test not only had great stability but it was also increasingly used by the participants after the interval. It is thought that the increase in the use of such strategy by the expected participants is the high exposure to the native language of learners.

c) Five of the strategies namely avoidance, restructuring, word coinage circumlocution, and self-pair (restructuring and word coinage were not differently used by control and experimental groups) had neither decline nor increase after the duration. To simply put, it could be argued that teaching these five strategies has stable effects on the learners' oral production.

According to the findings obtained from the first posttest compared with those in the second posttest, we can conclude that four out of the seven strategies which were significantly different in control and experimental groups were 
stable. Taking the abovementioned results gained from the first and the second posttest into account, it could be argued that CS instruction seems promising. Moreover; the findings of the present study has thrown light on the implementation of CS instruction in communicative situations of ESL classroom. Firstly, this study has sought to emphasize awareness-raising and CS use in challenging situations in order to assist learners to prevent interruption in communication events. Secondly, the frequency of strategy use can remain stable even when training and practice of these strategies have stopped.

However, the findings of this study are to some extent different from those of the previous researchers who have worked on the teachabilty of communicative strategies. As it was mentioned in review of literature of this study, there are two broadly diverging schools of thoughts on CSs. One approach focuses on the cognitive processes involved in selecting one or another strategy, and proponents of this approach including Bialystock (1990) believe that cognitive processes are unaffected by instruction and because CSs are part of cognitive processes, they are not teachable. The other approach, however, focuses on the linguistic expressions used in identifying types of CSs, and proponents of this approach (Konishi \& Tarone, 2004; Lam, 2005) advocate the necessity to teach these linguistic expressions or communicative strategies needed for effective L2 communication language use.

It could be finally discussed that $t$ both of the above mentioned points of view are right. On the one hand the first view claims that these are cognitive processes that select various types of the communicative strategies and the proponents of this view believe that cognitive processes are unaffected by instruction. This belief is right because before teaching communicative strategies, in both treatment and no-treatment conditions the learners' production in the pre-test showed the existence of these strategies. In other words; the participants used various types of communicative strategies before any teaching. On the other hand, the views which focus on the teachability of communicative strategies are right. The truth of this idea results from the findings of the first posttest.

Accordingly, both viewpoints are right. But the difference is that the proponents of the first view adheres to the cognitive nature of the strategies and ignores the external attempts for the consciousness-raising of these strategies. The question which could be raised concerning teachability of CSs is that if a process is cognitive, does it necessarily mean that it cannot be raised consciously? As a final point, instruction can be defined as turning unconsciousness into consciousness. Definitely, either unconsciously or consciously learners use communicative strategies, but explicit instruction of these strategies makes the learners conscious and also stabilizes the use of these strategies when essential.

\section{IMPLICATIONS}

This study has both theoretical and practical implications. Theoretically speaking, this study will reveal the effect of teaching communicative strategies on language performance of language learners in general and Iranian foreign language learners in particular. Among all communicative strategies investigated in this study are avoidance, approximation, restructuring, language switch, word coinage, appeal for assistance, circumlocution, self-repetition, selfrepair. On the whole, in the present study, one theoretical question to which great importance is attached is whether communicative strategies can be instructed explicitly or not. It is argued that even the most hardworking teachers spending lot of time on task cannot guarantee learners' achievement in communication. The steps taken are good, but they are not adequate to get language learners out of challenging communicative situations. Similarly, this study is theoretically significant in because it examines the effect of communicative strategies instruction on language performance of language learners. The findings of this study would be helpful for language learning theorists in that they would be familiar with the role of communicative strategies in learning English as a foreign language and they would be able to develop new theoretical ideas for favorable performance.

Pedagogical Implications

Undoubtedly, finding some strategies and procedures for acceptable communication has always been of interest for teachers, syllabus designers, and textbook and curriculum designers. It is hoped that the insights gained from this study can pave the ground for producing invaluable information for devising appropriate materials and effective teaching techniques suitable for different groups of learners at various stages of language learning. Based on the findings of the study, several recommendations for teaching English as a foreign language can be made. First, the present study demonstrates that including CS in SL materials especially textbooks and also devoting vigorous exercises to these strategies, teaching and practicing them in a special time of the classroom and most importantly equipping SL/FL learners with these CSs, can pave the ground for fruitful results. Undoubtedly, using these CSs by learners let them get out of difficult communicative situations.

Second, just hardworking on the part of language teachers without the inclusion of some of constructive strategies cannot solve the problem of disinclination of language learners in communicative events and those who are in charge of language instruction should keep in mind that one of the most important factor whose presence is fully essential in language teaching and learning is the instruction of communicative strategies and involving learners in practicing and using these strategies in their language production.

\section{REFERENCES}

[1] Bialystok, E. (1990). Communication Strategies. Oxford: Basil Blackwell. 
[2] Dorney, Z. (1995). On the teachability of communication strategies. TESOL Quarterly, 29, 55-58.

[3] Færch, C., \& Kasper, G. (1983). Plans and strategies in foreign language communication. In C. Færch \& G. Kasper (Eds.), Strategies in interlanguage communication (pp.20-44). London: Longman

[4] Konishi, K., \& Tarone, E. (2004). English constructions used in compensatory strategies: Baseline data for communicative EFL instruction. Electronic Journal of Foreign Language Teaching 2006, Vol. 3, No. 2, pp. 142-157

[5] Lam, W. Y. K. (2005). Is strategic competence teachable? The journal of Asia TEFL, 2, 87-112.

[6] Mariani, L. (1994). Developing Strategic Competence: Towards Autonomy in Oral Interaction Perspectives. A Journal of TESOL, Italy, Vol.20. No.1

[7] McDonough, S. H. (2006). Learner strategies. ELT Journal, 60, (1), 63-70.

[8] Nakatani's, Y. (2005). The effect of awareness-raising training on oral communication strategy use. The Modern language Journal, Vol 89,1, 76-91.

[9] Palmer, A. S. (1981). Measurements of reliability and validity in two pictures-description tests of oral communication' in A. S. Palmer, P. J. M. Groot, and G. A. Language Testing Journal, 4, pp.28-47.

[10] Poulisse, N. (1989). The use of compensatory strategies by Dutch learners of English. Unpublished doctoral dissertation, University of Nijmegen, the Netherlands.

[11] Rossiter, M. J. (2003). It's like chicken but bigger': effects of communication strategy in the ESL Classroom. The Canadian Modern Language review, 60, 105-121.

[12] Salamone, A.M., \& Marshale, F. (1972). How to avoid language breakdown? Circumlocution! Foreign Language Annals, 30,4 , 473-84.

[13] Savignon, S. (1972). Communicative competence: An Experimental in Foreign Language teaching. Philadelphia: Center for Curriculum development.

[14] Scullen, M. E. \& Jourdian, S. (2000). The effect of explicit training on successful circumlocution: A classroom study. Form and meaning.

[15] Selinker, L. (1972). Interlanguage. IRAL. 10,209-31.

[16] Tarone, E. (1977). Conscious communication strategies in interlanguage. A progress report. In H. D Brown, C. A. Yorio, \& R. C. Crymes (Eds), On TESOL 77. pp. 194-203. Washington, DC: TESOL.

[17] Varadi, T. (1973). 'Strategies of target language learner communication strategy'. TESOL Quarterly, 15, $285,295$.

[18] Wenden, A. (1986). Helping language learners think about learning. ELT Journal, 40, 3-12.

Goudarz Alibakhshi is an assistant professor of applied linguistics at Yasouj University. He has published several papers in international journals. He has also been teaching applied linguistics, language assessment, teaching methodology, ESP, and research methodology at Iranian state universities for a couple of years. He has presented several papers at national and international conferences.

Davoud Padiz is lecturer at Yasouj University. He has graduated from Yazd University and has been teaching English at Yasouj University as well as high schools since 15 years ago. He is interested in language teaching methods and research methodology. 